that is, exhumed planes of unconformity, have been finished, if not formed, by marine agency. In many such cases it is clear that the drainage pattern has not been inherited from a previous cycle, as must inevitably be the case with a true peneplain. Thus, closely spaced wind-gaps in the Old Red Sandstone ridges of southern Ireland indicate a consequent drainage initiated upon the surface which bevelled the structures. Similarly, the transection of anticlinal lines by rivers in southern England indicates that over wide areas the drainage originated upon the emergent floor of a Pliocene sea. Nevertheless, the whole of the region was not submerged; in parts of the Chalk areas of Wessex and the central Wealden area the reconstructed hill-top plane reveals the characteristics of a true peneplain and the drainage was adjusted accordingly. It seems, moreover, that the Thames in earlier stages of its history cut wide benches by lateral corrasion which may fairly be grouped with Crickmay's 'panplains' and the American examples adduced by Dr. Dunham.

The discussion gave a clear indication, if such be needed, that the findings of geomorphology in the field of erosion surfaces now challenge the close attention of the stratigraphical geologist and the geophysicist. Erosion surfaces, some trimmed by marine erosion and others demonstrably of sub-aerial origin, have been proved to have a wide extension and to maintain essentially unwarped attitudes over great distances. As such, they constitute an important record of the later geological history of the continents, supplementing the sometimes scanty evidence of deposition. Further, their existence cannot be ignored by those who seek to understand the nature and extent of isostatic adjustment in the lithosphere.

S. W. WOOLDRIDGE.

\title{
Physics in the Textile Industries
}

$\mathrm{R}$ ESEARCH physicists working in industry continue to increase in number, and the Institute of Physics, by holding conferences on industrial physics, does much to bring them together to discuss their mutual problems. But the conferences are open to all interested, and the physicist has opportunities of making contacts with those of other professions whose problems are essentially physical.

The third conference, held in Leeds during March 2325, was devoted to "Physics in the Textile Industries". The textile industries have been built up by many years of experimenting coupled with notable inventions, and it has behind it a wealth of knowledge which must be learnt by the physicist if his work is to be of utmost advantage to the industry. Meetings such as that held in Leeds are thus of great value in enabling the physicist to discuss problems not only with other physicists, but also with those conversant with the industry. Simultaneously, the industrial technical man has an opportunity of learning possible applications of physics and physical devices to his industry. This is particularly important for the older textile industries, where few factories have physicists on their permanent staff, and advances which physics has to offer must be introduced and cared for by the technical men.

The conference was held in the Physics Department of the University of Leeds. It was formally opened by the Vice-Chancellor, Mr. B. Mouat Jones, and was presided over by Prof. R. Whiddington. Following established practice of the Institute, the lectures and discussions were informal, and will not all be published.

The formal opening was followed by an address by Prof. Whiddington on "The Physics of Humidity". $\mathrm{He}$ discussed with demonstrations the properties of the small but important amounts of water in the atmosphere, and indicated why relative humidity is for the textile industries a much more convenient measure of the quantity of water vapour in the air than the fundamental measure, vapour pressure. $\mathrm{H}_{\Theta}$ then described properties of substances dependent on water content, and illustrated experimentally the large heat effects associated with change in water content of textile fibres. He concluded with an experi- ment showing the swelling of a wool fibre with increase of water content, using as a micrometer the capacity of a condenser in a heterodyne circuit. Thursday morning's programme was completed by a lecture from Dr. Ezer Griffiths, of the National Physical Laboratory, on "Industrial Humidity Control and Measurement". He illustrated with many slides the requirements of humidifying plant and humidity controls, and described the various ways of measuring relative humidity, indicating the method most convenient to each industrial process where this is important.

The afternoon of March 23 was devoted to a visit to the Department of Textile Industries in the University, followed by Dr. C. C. Paterson's presidential address to the Institute of Physics. He chose as his subject "Colour and Colour Rendering". This was a lecture of exceptionally beautiful and instructive demonstrations. Dr. Paterson pointed out the high efficiency attainable from discharge tube lamps, and contrasted their spectra and colour-rendering properties with daylight and other sources of illumination. The colour triangle and C.I.E. units were simply and elegantly explained, and there followed striking demonstrations of the difference between matched white lights for colour rendering. He pointed out that the appraisement of colour matching value is a pressing but unsolved problem. The lecture concluded with illustrations of the improvement in colour quality and efficiency attainable in discharge tube lamps by use of fluorescent materials.

The lectures on March 24 were by Dr. M. C. Marsh, of the Cambridge Instrument Co., Ltd., who chose "The Contribution of Physics to the Development of Industrial Process Control", and by Mr. D. Harrison, who spoke on "Automatic Regulators for the Textile Industries". These lectures brought to the notice of all the many instruments now available for industry, and features of their design gave an impressive illustration of the potentialities of physical krowledge when applied to industry.

The final lecture of the meeting was on "Heat Effects in Fibres and other Systems". It was given by Dr. C. G. Darwin, director of the National Physical Laboratory. It was a delightful lecture on a difficult 
and controversial subject. Kinetic effects have of recent years been used to explain the long-range elasticity of many natural substances, particularly rubber, and suggestions have from time to time been made that the same principles may lie behind the exceptional elasticity of muscle, wool fibres, and various synthetic materials. Dr. Darwin outlined the thermodynamic and statistical arguments of equipartition of energy and entropy, and used them in a critical survey of explanations of long-range elasticity. He showed, too, how these same kinetic principles led to the use of adiabatic demagnetization for attainment of very deep temperatures.

On Friday evening and Saturday morning, members of the Conference saw much of science in the textile industries at the laboratories of the Wool Industries Research Association. Alternative visits on Saturday morning to the Bradford Conditioning House and to Messrs. Prince-Smith and Stells, Ltd., Keighley, enabled members to appreciate the extent of testing of textile materials, and the ingenuity that has been used in design of textile machinery.

An exhibition of apparatus, instruments and books cognate to the subject of the conference was held in the physies laboratories of the University. Twentysix firms and research organizations, including the National Physical Laboratory, had stands at the Exhibition. A special section devoted to fopular applications of physics calculated to demonstrate its varied application to everyday matters, especially in the manufacture and use of textiles, aroused much interest. Representative instrument makers contributed exhibits which served to show how many and varied are the instruments available to help the textile manufacturer overcome many of the difficulties inherent in producing a uniform product from variable raw materials. The exhibition was of inestimable value in suggesting to textile manufacturers the large variety of problems that physics may tackle.

The Institute of Physics assumed a difficult task in choosing "Physics in the Textile Industries" as the subject for its third conference. Physics is becoming better recognized by textile manufacturers, but jts progress in the industry has proved difficult and slow. The success of the conference and the attention it has attracted should advance the application of physics in one of the largest industries of Great Britain, and in turn help it to meet ever-increasing competition from abroad.

\section{Forest Administration in Malaya}

\begin{abstract}
THE Forestry Department of the Straits Settlements and the Federated Malay States was organized in 1901 and the Malayan Forest Service, which includes all senior officers serving in Malaya, was created in 1926. Afterwards, the protected States of Johore (1920), Kedah (1923), Kelantan (1933), Brunei (1933) and Trengganu (1936) set up forestry departments of their own, to the charge of which officers of the Malayan Forest Service were appointed. A Research Branch was commenced in 1918, and has greatly developed and undertaken important work, its sections now consisting of botany, wood anatomy, sylviculture, chemistry, entomology, forest economy and timber testing. In connexion with the Research Branch, a vernacular school is maintained for the training of the subordinate staff. The Research Branch and School are now much on the same lines as the elassic example at Dehra Dun, India.

Decentralization took place in 1935, and the Malayan forest organization is now defined as a group of ten forest departments held together by a common and interchangeable staff of trained officers "with a central coordinating body (including the director of forestry), with executive control in some territories and advisory duties in others, that always exerts some influence towards co-operation and a broadly common forest policy". So long as the central co-ordinating body is listened to, progress in the future should be as good and better than the past. But decentralization is a dangerous thing in forestry - as can be seen in many parts of the forestry world in the British Empire. The required area of forests to be reserved in the interest of the individual country as a whole, stock mapping in forests under exploitation or shortly to be exploited, and, that safeguard of the forests, the working plan-these three essentials to a correct administration of a country are in one or more cases, and often in all three, lagging seriously behind what is needed in many parts of the Empire.
\end{abstract}

When this is the position-and in how much of our Empire outside India is this the case- decentralization and the withdrawal or even lightening of the control of a central authority responsible for a large region of country is seriously to be deprecated.

That this latter contention merits attention is shown by the statement contained in the "Annual Report on Forest Administration in Malaya for 1937" (F.M.S. Govt. Press, Kuala Lumpur, 1938). The Director writes, "Some uneasiness has however been caused by sudden and unexpected demands for the release of extensive areas that have always been regarded as permanent reserves. Thus, in Tahang the Tekai reserve of 83,000 acres had to be relinquished for inclusion in the King George V National Park, in this way preventing the exploitation of some particularly good merbau forest, conveniently situated near the railway. In Perak practically the whole of Pasir Panjang Ulu reserve of 19,000 acres was earmarked for a padi irrigation scheme, innumerable applications were received for permits to prospect for minerals and a strong bid was made by Sakai to settle in an old-established reserve that is by no means too large to meet the needs of the surrounding population and in which regeneration operations have been carried out for years at considerable expense to Government. This department is far from being unsympathetic to the claims of these various communities and realizes that adjustments will be necessary, but the long-range policy that is inseparable from conservative forestry makes it imperative that conflicting interests should be planned far enough in advance to enable systematic forest operations to be undertaken with some prospect of fruition".

Sympathy may be expressed with a department placed in such a situation, but the forestry authorities do not appear to understand that it is one of the objects of and duties of the working plan to safeguard forests from calamities of this type and others. 